\title{
Treatment of pulmonary exacerbations of cystic fibrosis leads to improved antioxidant status
}

\author{
S.P. Range*, C. Dunster**, A.J. Knox*, F.J. Kelly**
}

Treatment of pulmonary exacerbations of cystic fibrosis leads to improved antioxidant status. S.P. Range, C. Dunster, A.J. Knox, F.J. Kelly. CERS Journals Ltd 1999.

ABSTRACT: Many cystic fibrosis (CF) patients have increased circulating levels of oxidation products and/or decreased antioxidant status. This study investigated whether treatment of pulmonary exacerbations decreased oxidative stress in CF patients.

Seventeen adult patients were studied at the beginning and end of treatment with intravenous antibiotics. Plasma concentrations of the antioxidants ascorbic acid, $\alpha$ tocopherol, uric acid and total reduced thiols, together with plasma retinol, lipid hydroperoxides, malondialdehyde and protein carbonyl levels were determined. Median (interquartile range) pretreatment and post-treatment levels were compared using the Wilcoxon signed rank test.

Clinical resolution was reflected by improved spirometry. Significant increases were observed in plasma ascorbic acid (pre 30.4 (15.7-38.6) $\mu \mathrm{M}$, post $35.2(27.3-49.6)$ $\mu \mathrm{M}), \alpha$-tocopherol (pre $19.7(13.6-25.2) \mu M$, post $25.2(19.3-31.6) \mu M$ ) and retinol (pre $1.9(1.5-2.5) \mu \mathrm{M}$, post $2.7(1.7-3.5) \mu \mathrm{M})$. No change in plasma total reduced thiols occurred following treatment (pre $409(366-420) \mu \mathrm{M}$, post $392(366-423) \mu \mathrm{M}$ ), whereas uric acid fell with treatment (pre $307(274-394) \mu M$, post $260(216-317) \mu M$ ). Neither plasma protein carbonyls or malondialdehyde levels altered with treatment (protein carbonyls pre $0.47(0.28-1.27)$, post $0.67(0.42-0.83) \mathrm{nM} \cdot \mathrm{mg}^{-}$protein ${ }^{-1}$; malondialdehyde pre $0.75(0.53-1.18)$, post $0.84(0.65-1.15) \mu \mathrm{M})$. Lipid hydroperoxides levels did decrease following treatment $(53(18-85)$ versus $17(10-55) \mathrm{nM})$.

This study demonstrated that treatment of infective exacerbations resulted in increased plasma levels of some antioxidant vitamins. No immediate change in plasma protein oxidation was observed, but lipid oxidation was decreased.

Eur Respir J 1999; 13: 560-564.
*Cystic Fibrosis Unit, Division Respiratory Medicine, Nottingham City Hospital, Hucknall Road, Nottingham, UK. **Lung Biology Group, Rayne Institute, St. Thomas' Hospital, London, UK.

Correspondence: S.P. Range

Cardiothoracic Dept

Derby City Hospital

Derby DE22 3NE

UK

Fax: 441332625502

Keywords: Antioxidant

cystic fibrosis

infective exacerbation

oxidative stress

Received: September 291997

Accepted after revision October 101998

S. Range was supported in part by the UK Cystic Fibrosis Trust and UK Medical Research Council.
Respiratory failure accounts for the vast majority of deaths in cystic fibrosis (CF). The last two decades have seen major advances in the understanding of the aetiology and pathophysiology of pulmonary disease in CF. In spite of this, the precise mechanism by which the basic underlying genetic defect leads to bacterial colonization, recurrent infection, pulmonary destruction and eventually respiratory failure is not fully understood. One possible mechanism of lung damage in CF is an increased level of oxidative stress resulting in oxidative damage of pulmonary tissues [1-3]. Highly reactive oxygen species (ROS) are produced in large numbers by neutrophils found within the airways of CF patients $[4,5]$. Antioxidant defences may also be depleted in CF owing to both the increased utilization of these defences and pancreatic maldigestion leading to reduced levels of blood antioxidants in patients not receiving supplementation [6-8].

Patients with CF have been shown to have higher circulating levels of the products of oxidative damage [7, 9, 10] and an increased excretion of these in their urine [11]. Intervention with antioxidant supplementation has been shown to reduce markers of oxidative stress in CF patients $[7,12]$. Recently, the quantity of lipid oxidation products in bronchoalveolar lavage samples has been correlated with the presence of pulmonary inflammation in children with
CF [13]. Plasma levels of lipid oxidation products have been shown to be correlated with the severity of pulmonary disease in CF [14].

$\mathrm{CF}$ is characterized by a background of chronic pulmonary bacterial colonization with intermittent periods of more severe pulmonary symptoms termed "exacerbations". Pulmonary inflammation increases during these periods and subsides with antibiotic treatment [15]. Alteration in the severity of infection and the inflammation secondary to the host response may modulate the severity of oxidative stress within the CF lung.

The purpose of this study was to investigate possible changes in oxidative stress in patients with CF undergoing treatment for an infective exacerbation with intravenous antibiotic therapy in an inpatient setting. It was hypothesized that treatment of a pulmonary exacerbation would decrease the oxidative burden, leading to a reduction in the level of products of oxidative damage, and an increase in antioxidant capacity. To test this hypothesis, the pretreatment and post-treatment plasma concentration of markers of both protein (protein carbonyls) and lipid oxidation (lipid hydroperoxides and malondialdehyde) were measured, together with plasma antioxidants (ascorbic acid, $\alpha$ tocopherol, uric acid and total reduced thiols). 


\section{Materials and methods}

\section{Study subjects}

The study population consisted of 17 patients (seven male) with a mean age of $26 \pm 5$ yrs admitted to the Nottingham Adult CF Unit. All patients had been diagnosed as having $\mathrm{CF}$ on the basis of clinical history, a sweat chloride concentration of $>70 \mathrm{mmol} \cdot \mathrm{L}^{-1}$, and in most cases a genotype consistent with $\mathrm{CF}$. The study was approved by Nottingham City Hospital Medical Ethics Committee, and all patients gave written informed consent. The diagnosis of a pulmonary exacerbation was made by the patient's physician based upon clinical symptoms and spirometry. All patients were colonized with either Burkholeria cepacia, Pseudomonas aeruginosa or a combination of the two organisms. Details of each patient's sputum microbial flora (cultured during the study), intravenous antibiotics received, length of treatment, and concomitant vitamin supplementation are shown in table 1.

\section{Study design}

Venous blood samples were collected within $24 \mathrm{~h}$ of commencing intravenous antibiotic treatment, and at the end of the antibiotic course. Patients' weight and spirometry were recorded at the time of blood collection. Samples were standardized with respect to time of day and ingestion of vitamin supplements or major meals.

Table 1. - Details of the microbiology, antibiotic treatment and vitamin supplementation of patients enrolled in the study

\begin{tabular}{lcccc}
\hline $\begin{array}{l}\text { Patient } \\
\text { No. }\end{array}$ & $\begin{array}{c}\text { Sputum } \\
\text { microbiology }\end{array}$ & Antibiotic & $\begin{array}{c}\text { Treatment } \\
\text { course } \\
\text { days }\end{array}$ & $\begin{array}{c}\text { Vitamin } \\
\text { supplements }\end{array}$ \\
\hline 1 & PA & AZLO & 8 & a \\
2 & PA & AZ, G & 12 & a \\
3 & PA, SA, Coli & I & 10 & b \\
4 & BC & AZLO, G & 14 & a \\
5 & PA, HI, SA & TAZ, T, AZ & 20 & a \\
6 & PA, SA & TAZ, T & 14 & c \\
7 & PA, SA & CEF, T & 14 & a \\
8 & PA, BC & CEF, G & 14 & a \\
9 & PA & CEF, T, DX & 15 & a \\
10 & BC & CEF, AZ, DX & 21 & a \\
11 & BC & M, CO & 10 & d \\
12 & PA & CEF, T & 9 & c \\
13 & BC & CEF, CO & 14 & none \\
14 & BC & CEF, T & 12 & none \\
15 & PA & AZ, T & 10 & none \\
16 & BC & M, G & 12 & none \\
17 & PA, HI, SA & CEF, T & 13 & none \\
\hline
\end{tabular}

Sputum microbiology: PA: Pseudomonas aeruginosa; SA: Staphylococcus aureus; Coli: mixed coliforms; BC: Burkholderia cepacia; HI: Haemophilus influenza. Antibiotics: AZLO: azlocillin; AZ: aztreonam; G: gentamicin; I: imnipenem; TAZ: tazocin; T: tobramycin; CEF: ceftazidime; DX: doxycycline; M: merepenem; CO: cotrimoxazole. Vitamin supplements: a: vitamin A 1,600 IU, vitamin E $220 \mathrm{mg}$; b: vitamin A 3,200 IU, vitamin E $240 \mathrm{mg}$; c: vitamin A 8,000 IU, vitamin E $200 \mathrm{mg}$; d: vitamin A 4,000 IU, vitamin E $150 \mathrm{mg}$ (all supplements are per patient per day).

\section{Methods}

Spirometry was measured using a Vitalograph Alpha spirometer (Vitalograph, Buckingham, UK). Blood samples were collected in heparinized tubes and kept on ice in the dark and processed within $30 \mathrm{~min}$. Plasma was extracted by centrifugation at $1,200 \times g$ at $4^{\circ} \mathrm{C}$, and stored at $-80^{\circ} \mathrm{C}$ until assayed. Plasma hydroperoxides were measured in a subset of six patients only as this required a more complex plasma preparation procedure: $3 \mathrm{~mL}$ blood was collected in heparinized tubes containing $30 \mu \mathrm{L}$ of both 2 $\mathrm{mM}$ butylated hydroxytoluene (BHT, dissolved in methanol) and $2 \mathrm{mM}$ desferoxamine mesylate. Samples were then centrifuged $\left(1,200 \times g, 10 \mathrm{~min}, 4^{\circ} \mathrm{C}\right)$ to extract the plasma. Plasma $(0.5 \mathrm{~mL})$ was mixed with $20 \mu \mathrm{L} 10 \mathrm{mM}$ BHT and $0.25 \mathrm{~mL} 0.2 \mathrm{M}$ citric acid. The lipid hydroperoxides were then extracted with $6 \mathrm{~mL}$ ice cold hexane, and the extract was dried under a stream of nitrogen and stored at $-80^{\circ} \mathrm{C}$ until assayed.

Determination of plasma ascorbic acid and uric acid was carried out by high-performance liquid chromatography (HPLC) with electrochemical detection, as described previously [10]. Total reduced thiols were assayed by the method of ELLMAN [16]. The HPLC determination of $\alpha$ tocopherol and retinol was based on the method of BIERI $e t$ al. [17] with the following modifications: $100 \mu \mathrm{L}$ aliquots of plasma were mixed with $100 \mu \mathrm{L}$ anhydrous HPLCgrade ethanol containing $5 \mu \mathrm{g} \alpha$-tocopherol acetate as an internal standard. This mixture was then extracted with 400 $\mu \mathrm{L}$ HPLC grade hexane. The hexane layer was removed and evaporated to dryness under a stream of nitrogen. The extract was then redissolved in $400 \mu \mathrm{L}$ HPLC-grade methanol and $100-\mu \mathrm{L}$ aliquots were analysed. A $7 \times 100 \mathrm{~mm}$, 5- $\mu \mathrm{m} \mathrm{C}_{18}$ column (Jones Chromatography, Hengoed, UK) was eluted with methanol-water $(39: 1 \mathrm{v} / \mathrm{v})$ at a flow rate of $1.0 \mathrm{~mL} \cdot \mathrm{min}^{-1}$. $\alpha$-Tocopherol was detected from its absorbance at $292 \mathrm{~nm}$, and retinol was detected at $325 \mathrm{~nm}$. $\alpha$ Tocopherol and retinol standards were run routinely for quantification purposes. It was assumed that the recovery of $\alpha$-tocopherol acetate (generally $70-85 \%$ ) accurately reflected the recovery of $\alpha$-tocopherol and retinol.

Malondialdehyde was assayed by HPLC with fluorescence detection as described previously [18]. Lipid hydroperoxides were assayed by HPLC with chemiluminescence detection as also described previously [10]. Plasma protein carbonyl content was determined by a colorimetric assay according to LEVINE et al. [19], but with the following modifications. Briefly, each sample was divided into two $100-\mu \mathrm{L}$ aliquots which were run in parallel throughout the assay. Four-hundred microlitres $10 \mathrm{mM}$ 2,4-dinitrophenylhydrazine (DNPH) in $2.5 \mathrm{M} \mathrm{HCl}$ was added to one of the $100-\mu \mathrm{L}$ aliquots (+DNPH sample), and $400 \mu \mathrm{L} 2.5 \mathrm{M}$ $\mathrm{HCl}$ to the other (-DNPH). The samples were incubated for $15 \mathrm{~min}$ at room temperature, with continual mixing. Protein was then precipitated with $500 \mu \mathrm{L} 20 \%$ (w/v) trichloroacetic acid (TCA), and the samples were centrifuged $\left(5 \mathrm{~min}\right.$ at $\left.14,000 \times g, 4^{\circ} \mathrm{C}\right)$. Supernatants were then decanted and discarded before the addition of $400 \mu \mathrm{L} 10 \%$ TCA (w/v) to both the "+DNPH" and "-DNPH" samples, followed by mechanical disruption of the protein pellet with mild sonication $(14 \mu \mathrm{m}$ wavelength for $10 \mathrm{~s})$, and then further centrifugation (conditions as above). Samples were washed three times in a 1:1 (v/v) absolute ethanol-ethyl acetate solution. On each occasion, samples were mixed 
and allowed to stand for $5 \mathrm{~min}$ in the wash solution before centrifugation and aspiration of the supernatant. The final pellet produced from these washings was redissolved in $1.0 \mathrm{~mL} 6 \mathrm{M}$ guanidine- $\mathrm{HCl}$ in $20 \mathrm{mM}$ potassium phosphate ( $\mathrm{pH}$ adjusted to 2.3 using concentrated $\mathrm{HCl}$ ). After centrifugation, the absorbance of each supernatant, both "+DNPH" and "-DNPH" samples, was read against a $6 \mathrm{M}$ guanidine- $\mathrm{HCl}$ solution blank using an LKB Ultraspec II (Cambridge, UK) at a wavelength of $370 \mathrm{nM}$. The carbonyl content for each sample was calculated from the Beer-Lambent law, using the molar extinction coefficient of DNPH, 22,000 M.cm ${ }^{-1}$, and corrected for nonspecific absorbance at $370 \mathrm{~nm}$ by subtraction of the absorbance associated with the "-DNPH" sample. In order to compare the carbonyl content of different samples, protein assays were performed on the "-DNPH" samples. Results are expressed as nmols.mg protein ${ }^{-1}$. The intra-assay variation associated with this assay was $<5 \%$, and the inter-assay variation was corrected for with aliquots of a positive control sample (a highly oxidized plasma sample of known carbonyl concentration) in each assay. The detection limit of sensitivity was determined as $2.5 \mathrm{nmol} \cdot \mathrm{mg}$ protein ${ }^{-1}$.

\section{Analysis}

Statistical analysis was performed using Unistat (Unistat, London, UK). Within-subject differences were not normally distributed (Shapiro-Wilk normality test); therefore, the data are expressed as the median (interquartile range) for each group pre and post antibiotic treatment. Differences between groups were analysed using the Wilcoxon signed rank test.
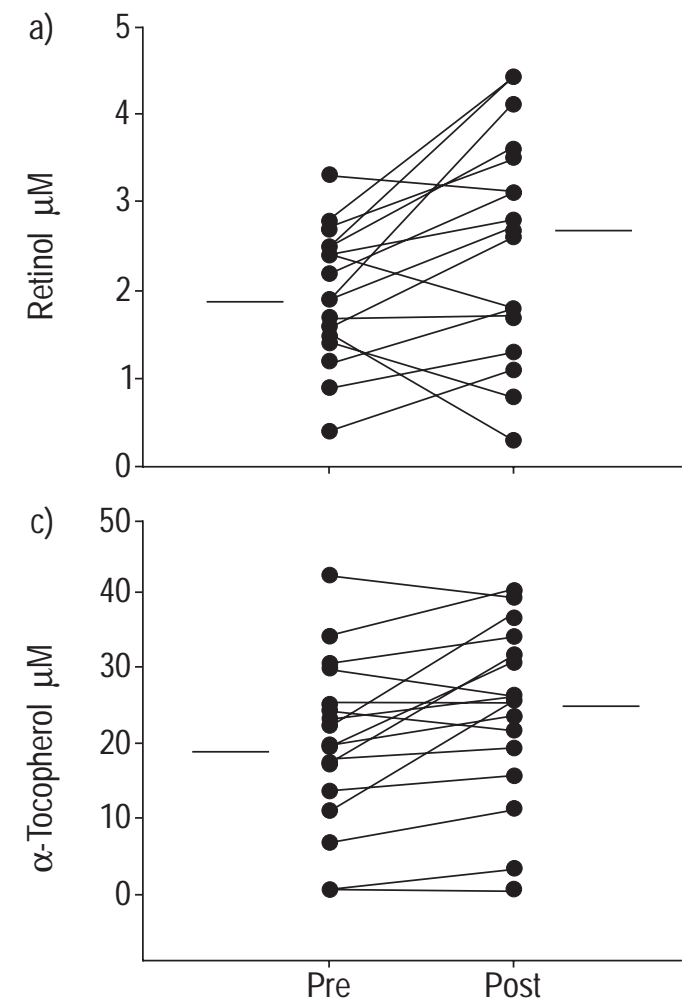

\section{Results}

Of the 20 patients that entered, 17 patients completed the study (three patients did not undergo a post-treatment assessment at their own request). The clinical resolution of exacerbation was reflected by improved spirometry (pretreatment forced expiratory volume in one second (FEV1) $0.91(0.59-1.57) \mathrm{L}$, post-treatment $1.09(0.83-1.77) \mathrm{L}, \mathrm{p}=$ $0.004)$.

The plasma ascorbic acid concentration increased following treatment (pre 30.4 (15.7-38.6) $\mu \mathrm{M}$, post 35.2 (27.3-49.6) $\mu \mathrm{M}, \mathrm{p}=0.012$, fig. 1). Similar increases in the plasma concentration of $\alpha$-tocopherol (pre 19.7 (13.625.2) $\mu \mathrm{M}$, post $25.2(19.3-31.6) \mu \mathrm{M}, \mathrm{p}=0.012$, fig. 1) and retinol (pre $1.9(1.5-2.5) \mu \mathrm{M}$, post $2.7(1.7-3.5) \mu \mathrm{M}$, $\mathrm{p}=0.02$, fig. 1) were also observed. No significant change in the plasma concentration of total reduced thiols occurred following treatment (pre $409(366-420) \mu \mathrm{M}$, post $392(366-423) \mu \mathrm{M}, \mathrm{p}=0.37)$. The plasma uric acid concentration fell with treatment (pre 307 (274-394) $\mu \mathrm{M}$, post 260 (216-317) $\mu \mathrm{M}, \mathrm{p}<0.001$, fig. 1).

No change in the plasma concentrations of malondialdehyde or protein carbonyls was observed. The plasma protein carbonyl concentration pretreatment was 0.47 $(0.28-1.17) \mathrm{nmol} \cdot \mathrm{mg}$ protein ${ }^{-1}$, post-treatment $0.67(0.42-$ $0-83) \mathrm{nmol} \cdot \mathrm{mg}$ protein ${ }^{-1}(\mathrm{p}=0.54$, whereas malondialdehyde was $0.75(0.53-1.18)$ pretreatment versus $0.84(0.65-$ 1.15) $\mu \mathrm{M}$ post-treatment $(\mathrm{p}=0.71)$. Pretreatment and posttreatment lipid hydroperoxide measurements were made in six patients. Of these, three subjects had detectable circulating lipid hydroperoxides that all decreased following treatment (pre 53 (18-85) versus post 17 (10-55) nM).
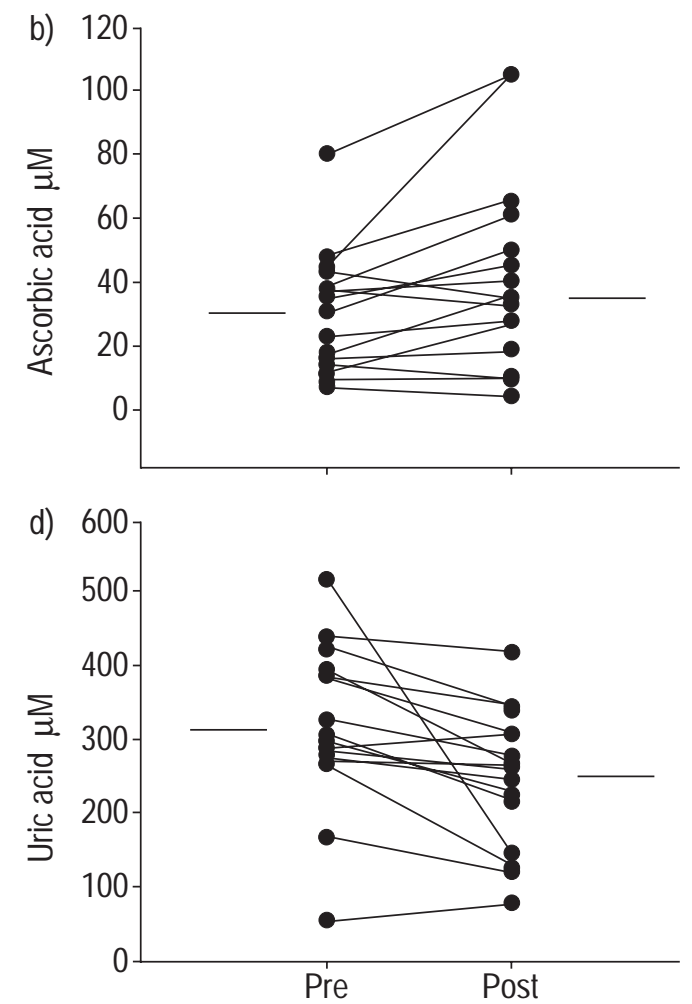

Fig. 1. - Effect of treatment on plasma antioxidants in 17 cystic fibrosis (CF) patients during an infective exacerbation. $\bullet$ : individual patient values; group medians. a) Retinol; difference between medians $\mathrm{p}=0.02$; normal plasma range $1.3-2.8 \mu \mathrm{M}$ [20]. b) Ascorbic acid; difference between medians $\mathrm{p}<0.01$; normal plasma range $11-66 \mu \mathrm{M}[20,21]$. c) $\alpha$-Tocopherol; difference between medians $\mathrm{p}<0.01$; normal plasma range $14.5-33.2 \mu \mathrm{M}$ [20]. d) Uric acid; difference between means $\mathrm{p}<0.01$; normal plasma range $50-900 \mu \mathrm{M}[22]$. 


\section{Discussion}

In this study, the hypothesis that the level of oxidative stress would be decreased following treatment of pulmonary exacerbations in $\mathrm{CF}$ was examined. This would be reflected as an increase in plasma concentrations of antioxidants and/or a decrease in plasma concentrations of markers of oxidative damage. Partial evidence was found in support of both proposals. Plasma concentrations of ascorbic acid and $\alpha$-tocopherol increased, whereas no change in the concentration of plasma total reduced thiols was seen with treatment. In addition, although the plasma concentrations of the end products of oxidative stress, malondialdehyde and protein carbonyls, did not change over the treatment period, lipid hydroperoxide levels, an early product in lipid peroxidation chain of events, did fall in patients who had these oxidation products prior to treatment.

The data presented in this paper were derived from measurements made in plasma samples. A major limitation to the interpretation of these data is that the majority of oxidation products probably arise within the respiratory tract. Hence, the relationship between plasma and lung levels of these oxidation products, and indeed antioxidants, may be crucial. Ideally the level of antioxidants and markers of oxidative damage in lung lining fluid would have been measured, but such highly invasive sampling in a comparatively sick group of patients is difficult to justify. Sampling of plasma antioxidants and markers of oxidative damage have been used previously to investigate oxidative stress in inflammatory lung disease [7, 9, 10, 12, 14], where again its limitations were recognized.

In agreement with studies carried out in two other UK $\mathrm{CF}$ units $[10,14]$ these patients were not, as a group, antioxidant-deficient. Several individuals were, however, well outside the accepted normal range for several antioxidants. Following treatment, there were marked improvements in the antioxidant status of some, but not all subjects. Moreover, those patients that did respond were not necessarily those with an initially poor antioxidant status (fig. 1). As a group, however, the changes were significant. Several factors may be responsible for the observed increase in plasma ascorbic acid, retinol and $\alpha$ tocopherol seen with treatment: the reduced infective burden following treatment leads to a reduction in neutrophil number and a reduction in neutrophil secretory products [15]. An associated reduction in neutrophil-derived ROS would thus be expected, which in turn would decrease the consumption of antioxidant vitamins such as ascorbic acid and $\alpha$-tocopherol.

Alternatively, the increase in antioxidant vitamin concentrations may be explained by an improvement in compliance with vitamin supplements during an inpatient stay. Compliance with vitamin supplementation in CF is often poor owing to the large therapeutic burden of these patients. This cannot, however, explain the increase in ascorbic acid concentration observed in 13 of the 17 patients as no patient received ascorbic acid as a supplement. In addition, in the five patients not receiving vitamin supplementation, an increase in retinol was observed in all following treatment (pretreatment $1.2(0.65-2.15) \mu \mathrm{m}$, post-treatment $1.8(1.2-3.1) \mu \mathrm{m}, \mathrm{p}=0.043)$. Plasma levels of $\alpha$-tocopherol increased in three unsupplemented patients, remained unaltered in one, and decreased in one (pre- treatment $19.7(10.1-24.7) \mu \mathrm{m}$, post-treatment $21.6(13.4$ 24.4) $\mu \mathrm{m}, \mathrm{p}=0.27)$.

A further explanation for the observed increases in plasma antioxidants seen in this study may be improved nutrition during the treatment period. Although the dietary intake was not formally quantified in this study, it would be expected that as the patients' infections resolve, nutritional intake would increase as they begin to feel better, with a corresponding increased intake of antioxidant vitamins.

Plasma uric acid concentration fell with treatment. Patients with CF often have a raised plasma uric acid, and this has been attributed to the high concentration of purines present in pancreatic enzyme supplements $[23,24]$. A further study in CF patients suggested that increased catabolism was the underlying explanation and that uric acid secretion was correlated with disease severity [25]. In the present study, the decrease in uric acid concentration observed following treatment is probably most likely due to reduced catabolism subsequent to the resolving infection.

Oxidative stress is generally considered to represent the imbalance between oxygen radical generation and available antioxidant defences. Although marked improvements in antioxidant status occurred in the majority of patients, these changes were not accompanied by any decrease in two primary end products of oxidative stress, malondialdehyde and protein carbonyls. This apparent lack of effect is puzzling given previous findings that demonstrate decreased malondialdehyde following treatment of exacerbations of chronic obstructive pulmonary disease [26]. Possible explanations for the present finding include: 1) the improvement in antioxidant status achieved in most patients was still not sufficient to overcome their oxidative burden; 2) sufficient time in the presence of the increased antioxidant status had not elapsed to have an impact on the circulating levels of these markers of oxidative stress; or 3) there is no direct correlation between antioxidant status and oxidant stress in CF patients. Some evidence to refute partially the second and third of these possibilities was found in those patients in which lipid hydroperoxides were found before treatment, as these fell following treatment. As lipid hydroperoxides are amongst the first products in the lipid peroxidation cascade, this finding suggests that the improved antioxidant status may have benefited these patients.

In conclusion, the present study has demonstrated that plasma ascorbic acid and $\alpha$-tocopherol concentrations increase following the treatment of infective exacerbations of cystic fibrosis. However, in the short term this improvement in antioxidant status does not appear to decrease the oxidative burden in these patients substantially.

Acknowledgements. The authors would like to thank G. Basten for help in preparing some of the samples.

\section{References}

1. Brown RK, Kelly FJ. Role of free radicals in the pathogenesis of cystic fibrosis. Thorax 1994; 49: 738-741.

2. van der Vliet A, Eiserich JP, Marelich GP, Halliwell B, Cross CE. Oxidative stress in cystic fibrosis: does it occur and does it matter. Adv Pharmacol 1997; 38: 491-513. 
3. Winklhofer-Roob BM. Oxygen free radicals and antioxidants in cystic fibrosis: the concept of an oxidantantioxidant imbalance. Acta Pediatrica 1994; 83: Suppl. 395, 49-57.

4. Babior BM. The respiratory burst of phagocytes. J Clin Invest 1984; 73: 599-601.

5. Witko-Sarsat V, Delacourt C, Rabier D, Bardet J, Nguyen AT, Latscha-Deschamps B. Neutrophil derived long-lived oxidants in CF sputum. Am J Respir Crit Care Med 1995; 152: 1910-1916.

6. Peters SA, Kelly FJ. Vitamin E supplementation in cystic fibrosis. J Pediatr Gastro Nutr 1996; 22: 341-345.

7. Lepage G, Champagne J, Ronco N, et al. Supplementation with carotenoids corrects increased lipid peroxidation in children with cystic fibrosis. Am J Clin Nutr 1996; 64: 87-93.

8. Homnick DN, Cox JH, Deloof MJ, Ringer DV. Carotenoid levels in normal children and in children with cystic fibrosis. J Pediatr 1993; 122: 703-707.

9. Portal BC, Richard M, Faure HS, Hadjian AJ, Favier AE. Altered antioxidant status and increased lipid peroxidation in children with cystic fibrosis. Am J Clin Nutr 1995; 61: 843-847.

10. Brown RK, Kelly FJ. Evidence for increased oxidative damage in patients with CF. Pediatr Res 1994; 36: 487493.

11. Brown RK, McBurney A, Lunec J, Kelly FJ. Oxidative damage to DNA in patients with CF. Free Rad Biol Med 1995; 18: 801-806.

12. Winklhofer-Roob BM, Ziouzenkova O, Puhl $\mathrm{H}$, et al. Impaired resistance to oxidation of low density lipoprotein in cystic fibrosis: improvement during vitamin $\mathrm{E}$ supplementation. Free Rad Biol Med 1995; 6: 725-733.

13. Hull J, Vervaart P, Grimwood K, Phelan P. Pulmonary oxidative stress response in young children with cystic fibrosis. Thorax 1997; 52: 557-560.

14. Brown RK, Wyatt H, Price JF, Kelly FJ. Pulmonary dysfunction in $\mathrm{CF}$ is associated with oxidative stress. Eur Respir J 1996; 9: 334-339.

15. Peckham DG, Crouch S, Humphreys H, Lobo B, Tse A, Knox AJ. Effect of antibiotic treatment on inflammatory markers and lung function in $\mathrm{CF}$ patients with Pseudomonas cepacia. Thorax 1994; 49: 803-807.

16. Ellman GL. Tissue sulphydryl groups. Arch Biochem Biophys 1959; 82: 70-77.

17. Bieri JG, Tolliver TJ, Catignani GL. Simultaneous determination of alpha-tocopherol and retinol in plasma or red cells by high pressure liquid chromatography. $\mathrm{Am} \mathrm{J}$ Clin Nutr 1979; 32: 2143-2149.

18. Kelly FJ, Blomberg A, Krishna MT, Frew AJ, Holgate ST, Sandstrom T. Antioxidant kinetics in lung lining fluids following exposure of humans to nitrogen dioxide. Am J Respir Crit Care Med 1996; 154: 1700-1705.

19. Levine RL, Garland D, Oliver CN, et al. The determination of carbonyl content in oxidatively modified proteins. In: Packer L, Glazer AN, Eds. Methods in Enzymology. London, Academic Press, 1990; pp. 464-477.

20. Gregory J, Foster K, Tyler H, Wiseman H. The dietary and nutritional survey of British adults. London, HMSO, 1990.

21. Committee on the Medical Aspects of Food Policy, Dept of Health. Estimates of plasma levels based on Vit C intake. Dietary reference values for food energy and nutrients for the United Kingdom. Series: Report on Health and Social Subjects. London, HMSO, 1997; p. 41.

22. Becker BE. Toward the physiological function of uric acid. Free Rad Biol Med 1993; 14: 615-631.

23. Stapleton FB, Kennedy J, Nouisa-Arvanitakis S, Linshaw MA. Hyperuricosuria due to high-dose pancreatic extract therapy in cystic fibrosis. $N$ Engl J Med 1976; 295: 246248.

24. Sack J, Blau H, Goldfarb D, Ben-Zaray S, Katznelson D. Hyperuricosuria in cystic fibrosis patients treated with pancreatic enzyme supplements. A study of 16 patients in Israel. Israel J Med Sci 1980; 16: 417-419.

25. Niessen KH, Wolf A. Studies on the cause of hyperuricosuria in cystic fibrosis patients. $J$ Pediatr Gastroent Nutr 1982; 1: 349-354.

26. Rahman I, Skwarska E, MacNee W. Attenuation of oxidant/antioxidant imbalance during treatment of exacerbations of chronic obstructive pulmonary disease. Thorax 1997; 52: 565-568. 